\title{
Laser-Guided Direct Writing for Three-Dimensional Tissue Engineering
}

\author{
Yaakov Nahmias, ${ }^{1}$ Robert E. Schwartz, ${ }^{2}$ Catherine M. Verfaillie, ${ }^{2}$ David J. Odde ${ }^{1}$ \\ ${ }^{1}$ Department of Biomedical Engineering, University of Minnesota, \\ 7-132 Hasselmo Hall, 312 Church Street, Minneapolis, Minnesota 55455; \\ telephone: (612) 626-9980; fax: (612)626-6583; e-mail: oddex002@umn.edu \\ ${ }^{2}$ Stem Cell Institute, University of Minnesota, MMC 716 Mayo, 420 Delaware St SE, \\ Minneapolis, Minnesota
}

Received 13 December 2004; accepted 20 April 2005

Published online 15 July 2005 in Wiley InterScience (www.interscience.wiley.com). DOI: 10.1002/bit.20585

\begin{abstract}
One of the principal limitations to the size of an engineered tissue is oxygen and nutrient transport. Lacking a vascular bed, cells embedded in an engineered tissue will consume all available oxygen within hours while out branching blood vessels will take days to vascularize the implanted tissue. One possible solution is to directly write vascular structures within the engineered tissue prior to implantation, reconstructing the tissue according to its native architecture. The cell patterning technique, laser-guided direct writing (LGDW), can pattern multiple cells types with micrometer resolution on arbitrary surfaces, including biological gels. Here we show that LGDW can pattern human umbilical vein endothelial cells (HUVEC) in two- and three-dimensions with micrometer accuracy. By patterning HUVEC on Matrigel, we can direct their self-assembly into vascular structures along the desired pattern. Finally, co-culturing the vascular structures with hepatocytes resulted in an aggregated tubular structure similar in organization to a hepatic sinusoid. This capability can facilitate studies of tissue architecture at the single cell level, and of heterotypic interactions underlying processes such as liver and pancreas morphogenesis, differentiation, and angiogenesis. (c) 2005 Wiley Periodicals, Inc.
\end{abstract}

Keywords: micropatterning; optical forces; liver tissue engineering

\section{INTRODUCTION}

Tissue architecture is complex, characterized by multiple cell types and matrix components precisely organized in threedimensions. Loss of tissue architecture due to trauma or disease leads to loss of tissue function. An important advance in tissue engineering would be the ability to organize multiple cell types in the well-defined three-dimensional architecture of their native organ, in essence reconstructing the tissue from its cellular and matrix components (Bhatia and Chen, 1999; Griffith and Naughton, 2002).

One approach to create such complex organization is micropatterning (Bhatia and Chen, 1999). Laser-guided direct writing (LGDW) is a novel micropatterning technique

Correspondence to: D.J. Odde able to confine multiple cells in a laser beam and deposit them as a steady stream on arbitrary non-absorbing surfaces, including biological gels. LGDW has micrometer scale accuracy and the potential to pattern cells in threedimensions (Chrisey, 2000; Nahmias et al., 2004; Odde and Renn, 1999). Other cell patterning methods, such as microcontact printing (Dike et al., 1999) or lithography (Bhatia et al., 1997), although offering important opportunities, are limited to patterning in two-dimensions, or offer limited spatial resolution $(>100 \mu \mathrm{m})$ in three-dimensions (Chiu et al., 2000; Liu and Bhatia, 2002). The single cell resolution, offered by LGDW, is required for the patterning of endothelial capillaries $(<10 \mu \mathrm{m})$, which were shown to be important for tissue development, differentiation, and survival (Cleaver and Melton, 2003).

The current inability to create a capillary network inside an engineered tissue restricts the tissue's size to within the oxygen and nutrient diffusion limit $(\sim 200 \mu \mathrm{m})$ (Griffith and Naughton, 2002). While some tissues can be encouraged to develop their own vascular network within days after implantation (Koike et al., 2004), high-metabolic-activity tissues, such as liver and heart, cannot survive more than a few hours without vascular support (Strain and Neuberger, 2002). One solution would be to use LGDW to establish capillaries within the engineered tissue prior to implantation. This technique makes feasible the creation of metabolically active tissues, such as liver, beyond the oxygen diffusion limit.

We have previously demonstrated LGDW's ability to guide embryonic chick neurons (Odde and Renn, 1999, 2000) and multi-potent adult progenitor cells (Nahmias et al., 2004). Here, we show that LGDW can be used to pattern human umbilical vein endothelial cells (HUVEC) in two- and three-dimensions. HUVEC patterned on Matrigel, a commonly used angiogenesis assay system (Kubota et al., 1988; Shakado et al., 1995), self-assembled into vascular structures along the pattern. Co-culturing the patterned vascular structures with hepatocytes resulted in an aggregated tubular structure similar in organization to a hepatic sinusoid. 


\section{MATERIALS AND METHODS}

\section{Materials}

Williams medium E, M199 basal medium, penicillin/ streptomycin, L-glutamine, sodium pyruvate, and insulin were purchased from Invitrogen Life Technologies (Carlsbad, CA). Glycine, dexamethasone, and heparin were obtained from Sigma-Aldrich (St. Louis, MO). Epidermal growth factor (EGF) and growth factor reduced phenol red free Matrigel were obtained from Fisher Scientific (Pittsburgh, PA), endothelial cell growth factor (ECGF) from Roche Applied Science (Indianapolis, IN), recombinant human vascular endothelial growth factor (VEGF) and hepatocyte growth factor (HGF) from R\&D Systems, Inc. (Minneapolis, $\mathrm{MN}$ ), fetal bovine serum (FBS) HI from Hyclone Laboratories (Logan, UT), and EndoGro from Vec Technologies (Rensselaer, NY). Immunofluorescence grade paraformaldehyde was purchased from Electron Microscope Sciences (Hatfield, PA). Normal donkey serum and secondary F(ab')2 antibody fragments, ML grade were obtained from Jackson Immunoresearch (Bar Harbor, ME). Mouse anti-human CD31, used at 1:10 dilution, was from Becton-Dickinson (San Diego, CA). Rabbit anti-rat albumin, used at 1:500 dilution, was from ICN (Costa Mesa, CA).

\section{Endothelial Cell Isolation and Culture}

Human Umbilical-Vein endothelial cells (HUVEC) were a kind gift from Dr. Robert Hebbel, University of Minnesota (Gupta et al., 1997). Cells were cultured on $0.2 \%$ gelatin coated T-75 flasks and split 1:3 when confluent. Endothelial culture medium consisted of M199 basal medium, 15\% FBS, EndoGro ( $40-50 \mathrm{mg} / \mathrm{mL})$, L-glutamine $(0.7 \mathrm{mg} / \mathrm{mL})$, heparin $(10 \mathrm{U} / \mathrm{mL})$, sodium pyruvate $(30 \mu \mathrm{g} / \mathrm{mL})$, and penicillin/streptomycin $(100 \mathrm{U} / \mathrm{mL})$. Cell medium was changed every 2 days.

\section{Hepatocyte Isolation and Culture}

Hepatocytes were harvested from 4- to 6-week-old male Sprague-Dawley rats weighing $175-275 \mathrm{~g}$ by a two-step in situ collagenase perfusion technique (Seglen, 1976). Hepatocyte viability after the harvest was above $80 \%$ based on trypan blue exclusion. All animals were treated according to protocols approved by the animal care institutional review board. Hepatocyte purity was greater than $95 \%$.

\section{MAPC Isolation and Culture}

Multipotent adult progenitor cells (MAPC) were isolated and cultured as previously described (Reyes et al., 2001, 2002; Schwartz et al., 2002). Briefly, bone marrow was obtained from Sprague-Dawley rats. Mononuclear cells were depleted for CD45 and glycophorin A positive cells using micromagnetic beads (Miltenyi Biotec, Sunnyvale, CA), seeded on fibronectin (Sigma) and cultured in MAPC expansion medium (Reyes et al., 2001, 2002; Schwartz et al., 2002).

\section{Preparation of Chamber Slides for LGDW}

Chamber slides were coated with a collagen thin layer, collagen gel, or Matrigel. Briefly, collagen solution (1 mg/ $\mathrm{mL}$ ) was absorbed for $1 \mathrm{~h}$ at $37^{\circ} \mathrm{C}$ and carefully washed with PBS. Collagen gelling solution was prepared according to manufacturer instructions, layered on ice-cold glass chamber slides $\left(0.5 \mathrm{~mm}\right.$ thickness, $\left.4 \mathrm{~cm}^{2}\right)$ and incubated at $37^{\circ} \mathrm{C}$ for $30 \mathrm{~min}$ to allow the gel to form. Matrigel aliquots $(200 \mu \mathrm{L})$ were thawed overnight at $4^{\circ} \mathrm{C}$, layered on ice-cold glass chamber slides $\left(0.5 \mathrm{~mm}\right.$ thickness, $\left.4 \mathrm{~cm}^{2}\right)$ and incubated at $37^{\circ} \mathrm{C}$ for $30 \mathrm{~min}$ to allow the gel to form. For the co-culture experiment, freshly isolated hepatocytes were added at a density of 40,000 cells $/ \mathrm{cm}^{2}$ in $1 \mathrm{~mL}$ of co-culture medium. Co-culture medium consisted of Williams Medium E, HEPES, pen/strep $(100 \mathrm{U} / \mathrm{mL})$, and insulin $(20 \mathrm{mU} / \mathrm{mL})$, which was stored for up to 4 weeks in $4{ }^{\circ} \mathrm{C}$. To use in culture experiments, the medium was supplemented once a week with $2 \%$ FBS, L-glutamine $(0.3 \mathrm{mg} / \mathrm{mL})$, dexamethasone $\left(10^{-8} \mathrm{M}\right)$, ECGF $(20 \mu \mathrm{g} / \mathrm{mL})$, heparin $(10 \mathrm{U} / \mathrm{mL})$, EGF, and $\operatorname{VEGF}(10 \mathrm{ng} / \mathrm{mL})$. Cells were allowed to attach over night at which time the medium was replaced with $1 \mathrm{~mL}$ of co-culture medium.

\section{Laser-Guided Direct Writing System Design}

A laser diode beam (model, 5431, SDL; $200 \mathrm{~mW}, 830 \mathrm{~nm}$ wavelength, $\mathrm{TEM}_{00}$ mode) was expanded vertically through an anamorphic prism pair to create a circular beam. The beam was focused through a low numerical aperture guidance lens (0.1NA, focal length $60 \mathrm{~mm}$, Edmund Scientific, Barrington, $\mathrm{NJ}$ ), and reflected by a $45^{\circ}$ gold-coated mirror (Edmund Scientific) into a sealed glass chamber slide set on an inverted (Axiovert S100TV, Zeiss, Thornwood, NY) microscope (Fig. 1). Images of the developing pattern were taken using a high-resolution CCD camera (Sony XC-75, Edmund Scientific) and digitally captured through a frame grabber board

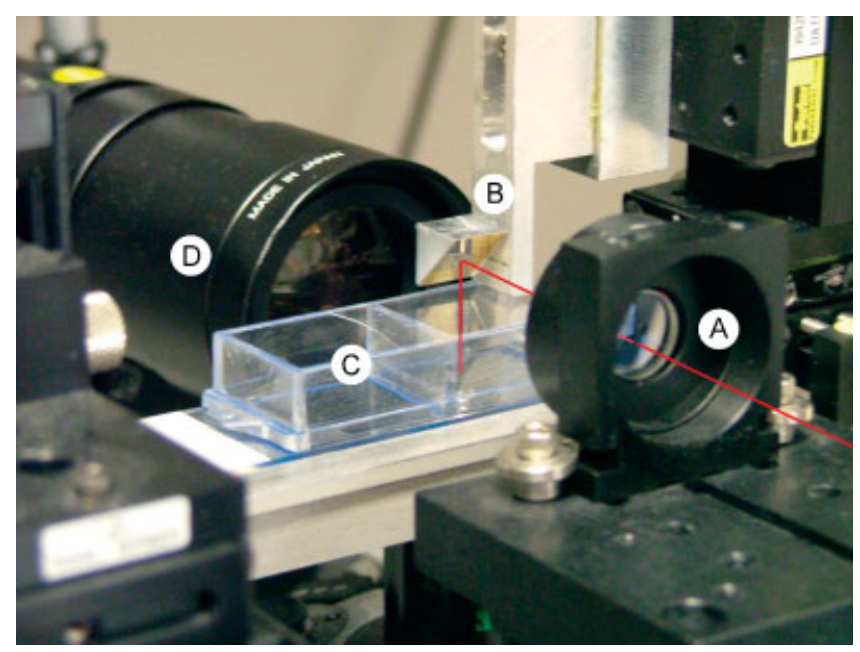

Figure 1. Laser-guided direct writing (LGDW) system. The beam path is highlighted schematically in red. A: Laser-guidance focusing lens $(12 \mathrm{~mm}$ diameter), (B) $45^{\circ}$ angle gold-coated mirror, (C) sealed glass chamber slide, (D) side-on imaging lens for monitoring particle path. 
(LG-3, Scion Corp, Frederick, MD). A wide angle telescopic $4 \times$ lens mounted perpendicular to the beam axis was used to monitor the trapping and movement of the captured particles (Fig. 1).

\section{Laser Guided Direct Writing Experiments}

HUVEC were cultured to a confluent monolayer on a $0.2 \%$ gelatin coated dish. Once the cells reached confluence, $50 \mathrm{~mL}$ of VEGF linked polystyrene beads $(4.5 \mu \mathrm{m}$ diameter, Polysciences, Warrington, PA) were added to the cell's culture medium. The VEGF beads rapidly adhered to the cells after an hour in culture. Following $1 \mathrm{~h}$ incubation with the VEGF beads, the culture was carefully washed with HBSS to remove non-adherent beads. Finally, the cells were quickly trypsinized off the surface to create a cell-bead suspension. An extracellular matrix-coated chamber slide (either collagen, or Matrigel) was prepared in advance (see above). One milliliter of Percoll solution (40\%) was added to the chamber to prevent cells from settling under gravity. Finally, the HUVEC-bead suspension was carefully layered on top of the Percoll solution. The entire setup was done under sterile conditions and the chamber was sealed with a glass coverslip. The chamber slide was subsequently moved to the LGDW system shown in Figure 1. Cells were radially trapped by the beam and axially pushed through the Percoll layer to the extracellular matrix-coated surface below. Cells that were not trapped by the beam remained floating above the density-matched Percoll layer. Following cell patterning, the chamber was incubated for $20 \mathrm{~min}$ to allow the cells to adhere and then carefully washed with HBSS.

\section{Transmission Electron Microscopy}

The cells were fixed in $2.5 \%$ glutaraldehyde in $0.1 \mathrm{M}$ cacodylate buffer ( $\mathrm{pH}$ 7.4) containing sucrose at room temperature for $30 \mathrm{~min}$, postfixed in $2 \%$ osmium tetroxide in the buffer, and embedded in situ in Epon 812. Semi-thin and ultra-thin sections were cut on Reichert Ultracut E and RMC MT-7000 ultramicrotomes. The semi-thin sections were stained with toluidine blue and examined with a light microscope. The adjacent thin sections were stained with uranyl acetate followed by lead citrate and examined at $60 \mathrm{KV}$ with a JEM transmission electron microscope (JEOL, Tokyo, Japan).

\section{Immunofluorescence Microscopy}

Chamber slide samples were washed three times with PBS, and fixed in 4\% EM-grade paraformaldehyde for $10 \mathrm{~min}$ at room temperature. Slides were then washed with PBS and incubated in $100 \mathrm{mM}$ glycine for $15 \mathrm{~min}$ to saturate reactive groups. Samples were permeabilized for 15 min with $0.1 \%$ Triton X-100, blocked for 30 min with 1\% BSA, 5\% Donkey Serum at room temperature followed by staining with primary antibodies overnight at $4^{\circ} \mathrm{C}$. After additional washes with PBS, samples were stained with fluorescently tagged secondary antibodies for $45 \mathrm{~min}$ at room temperature.

\section{RESULTS AND DISCUSSION}

\section{General Analysis of the LGDW System}

LGDW utilizes a weakly focused beam to radially trap and axially deliver particles to a non-absorbing surface. By translating the surface relative to the beam, the particle stream can be directly written onto the surface. We have previously demonstrated the ability of LGDW to guide metal droplets, silica and polymer beads, bacteria, and animal cells (Odde and Renn, 2000; Renn et al., 1995; Renn and Pastel, 1998). In addition, we demonstrated patterning of embryonic chick neurons (Odde and Renn, 1999) and multi-potent adult progenitor cells (Nahmias et al., 2004).

However, patterning endothelial cells proved to be a greater challenge due to the cells' low refractive index ( $1.35 \pm 0.01$ by index matching), which limited the optical force. Dimensional analysis of theoretical optical forces is presented in Table I following Nahmias et al. (2004). The theoretical analysis shows that a $4 \%$ decrease in refractive index from that of MAPCs (1.40) to that of endothelial cells (1.35) will result in a fourfold decrease in the relative trapping force and a 25-fold decrease in the pushing force. One approach to achieving reasonable trapping and guiding forces for endothelial cells is to attach polystyrene particles to the cells (optical handles). As the optical forces should be additive, it is estimated that between 2 and 5 polystyrene particles attached to an endothelial cell will significantly improve system performance and enable us to pattern endothelial cells on arbitrary surfaces.

To test this hypothesis, we added VEGF-linked polystyrene beads ( $4.5 \mu \mathrm{m}$ diameter, 1.55 refractive index), which rapidly adhered to the cells. In accordance with theory, the

Table I. General analysis of optical force for biological and non-biological particles.

\begin{tabular}{|c|c|c|c|c|c|c|}
\hline Particle type & Radius $(\mu \mathrm{m})$ & Refractive index & $\tilde{\alpha}$ & $\beta$ & Relative radial force & Relative axial force \\
\hline MAPC & 6 & 1.40 & 1.2 & 12.49 & 0.88 & 5.50 \\
\hline Chick neuron & 6 & 1.38 & 1.2 & 12.49 & 0.63 & 2.84 \\
\hline Endothelial & 5 & 1.35 & 1.0 & 6.02 & 0.21 & 0.22 \\
\hline Polystyrene & 2.25 & 1.55 & 0.45 & 0.25 & 1 & 1 \\
\hline
\end{tabular}

Dimensionless parameters, $\tilde{\alpha}$ and $\beta$ were calculated as previously described (Nahmias et al., 2004) for beam waist at the focal point $5 \mu \mathrm{m}$, and wavelength $830 \mathrm{~nm}$. Relative radial and axial forces were calculated relative to $4.5 \mu \mathrm{m}$ diameter polystyrene particles, and by using the relationship that the axial force is proportional to $\left(\frac{m^{2}-1}{m^{2}+2}\right)^{2}$, while radial force is proportional to $\left(\frac{m^{2}-1}{m^{2}+2}\right)$. 
HUVEC-bead suspension was easily trapped and rapidly delivered to the surface. Similar results were obtained for collagen and laminin-linked beads, while plain beads failed to adhere to the cells. The cells exhibited no discernable reaction to the beads. Beads became dilute as the cells migrated and proliferated and were released over time in culture ( $\sim 10 \%$ per day). The widespread use of magnetic beads of similar diameter $(4.5 \mu \mathrm{m})$ to purify endothelial cells from tissue (Bicknell, 1996), suggests that inert polystyrene beads should not affect the biological function of our cultures.

\section{Endothelial Cell Viability Following LGDW}

Figure 2 shows a three-line pattern of HUVEC $24 \mathrm{~h}$ after LGDW. The cells were normal and well spread, forming the usual cobblestone morphology in areas where sufficient cell density exists. Endothelial viability after laser guidance was measure by trypan blue exclusion to be $89 \% \pm 7 \%$ (mean \pm standard deviation). Endothelial viability was not statistically different from cell viability during regular passage $(97 \% \pm 1 \%)$. As expected, the cells migrated off the pattern and proliferated a few days after guidance. This result, in agreement with our previous results for chick neurons (Odde and Renn, 1999) and two decades of laser trapping experiments (Ashkin, 1997), suggests that LGDW has no overt negative effect on the patterned cells, in stark contrast to the adverse effects of ultraviolet radiation used in photopatterning (Liu and Bhatia, 2002).

\section{Three-Dimensional Cell Writing With LGDW}

Several groups have demonstrated the importance of threedimensional culture for the preservation of cellular phenotype (O'Brien et al., 2002). For example, hepatocytes cultured in a gel 'sandwich' configuration retained their polarity and liver specific function for weeks in vitro (Dunn

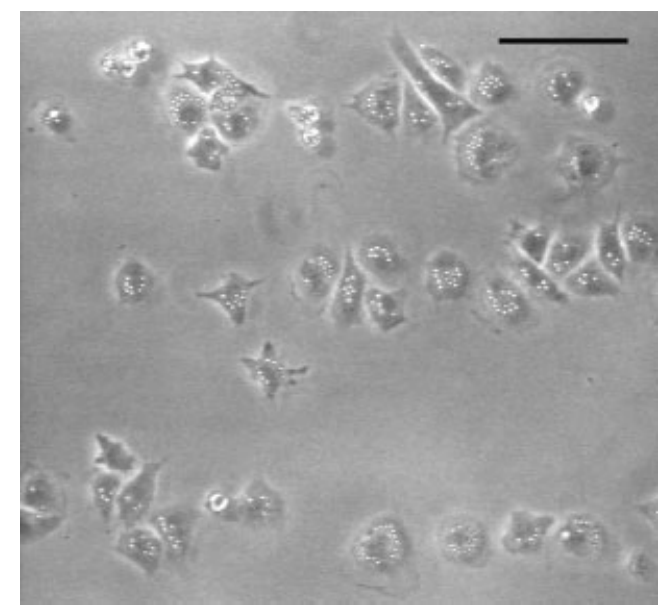

Figure 2. Three line pattern of HUVECs written on a collagen-coated surface by LGDW. Twenty-four hours after guidance, cells appear healthy and well spread. HUVECs patterned in this way continued to migrate and proliferate as normal after LGDW. Bar $=100 \mu \mathrm{m}$. et al., 1991). Similar culture systems stimulate endothelial assembly into vascular structures (Deroanne et al., 2001). These results suggest that the three-dimensional environment is important for proper tissue function. As LGDW can be applied to arbitrary non-absorbing matrix, cellular patterns can be written on top of previous patterns encased in gel. This would allow the consecutive building of three-dimensional structures as shown schematically in Figure 3.

Using this approach, a three-dimensional pattern of HUVECs is presented in Figure 4. Three lines of HUVEC were written on a collagen-coated surface and allowed to adhere. The media was aspirated and a collagen gel $(0.5 \mathrm{~mm}$ high) was carefully layered on top of the first pattern. An additional pattern of three lines of cells was written, oriented perpendicular to the first pattern, on top of the gel to create a three-dimensional pattern. Currently, LGDW is the only cell patterning technique able to pattern cells with micrometer precision on biological gels. In addition to LGDW ability to pattern cells on biological gels, we demonstrate its ability to place one cell on top of another in a true three-dimensional pattern. Figure $4 \mathrm{C}$ shows three cells patterned on top of each other, viewed at right angle to the deposition axis. We conclude LGDW can deposit cells on arbitrary surfaces including biological gels and living cells.

\section{Directed Writing of Endothelial Vascular Structures}

A key step of tissue engineering would be the construction and maintenance of a three-dimensional structure. The limiting factor in this endeavor is frequently one of oxygen and nutrient transport (Griffith and Naughton, 2002). One approach would be to directly write endothelial vascular structures within the engineered structure, thus reconstructing the tissue according to its native architecture. This method has the advantage of retaining the natural heterotypic cell-cell interactions of the native tissue, which have been

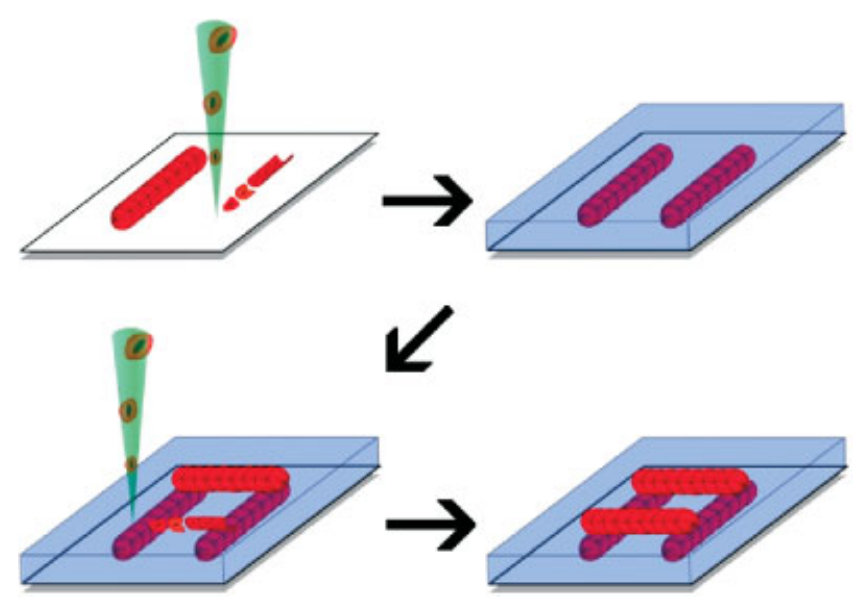

Figure 3. Use of LGDW for three-dimensional tissue engineering. Endothelial lines are patterned on a two-dimensional surface and then selfassemble into vascular structures. A thin gel is layered on top of the first pattern. Another pattern can now be created on the top surface. 

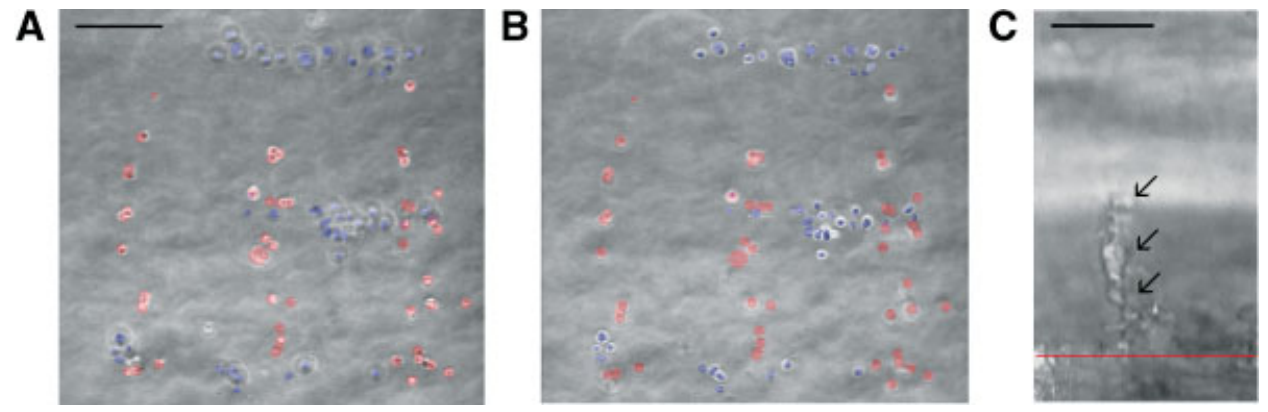

Figure 4. LGDW in three-dimensions. A, B: Three vertical lines of HUVEC were written on a collagen-coated surface (red pseudocolor), and a collagen gel overlaid. A pattern of three horizontal lines was written on top of the first pattern (blue pseudocolor). A: Image is focused on the bottom vertical (red) lines of cells. B: Image is focused on the top horizontal (blue) lines of cells. Images were taken $2 \mathrm{~h}$ after LGDW. Bar $=200 \mu \mathrm{m}$. C: Three cells (arrows) deposited on top of each other, image taken perpendicular to the axis of deposition. The red line denotes the position of a collagen-coated surface. Bar $=50 \mu \mathrm{m}$.

previously shown to be important in tissue function (Bhatia et al., 1999; Goulet et al., 1988).

Utilizing the ability of endothelial cells to rapidly form a tube-like network when cultured on Matrigel, a commonly used angiogenesis assay (Auerbach et al., 2003), we patterned three lines of HUVEC on Matrigel using LGDW. The endothelial cells elongated and formed tube-like structures along the pattern, demonstrating the capability of LGDW to pattern vascular structures in vitro (Fig. 5). These results demonstrate our ability to pattern endothelial vascular structures in vitro with micrometer accuracy. However, the stabilization and maturation of these vascular structures into fully functional capillaries would undoubtedly require a more precise control of their microenvironment (shear, matrix, growth factors) in addition to their co-culture with cells of their native environment (Koike et al., 2004).

\section{Directed Writing of Sinusoid-Like Structures}

One of the structural elements of the liver is the sinusoid, composed of a fenestrated vascular structure decorated with hepatocytes. In the adult liver, sinusoids are radially aligned, running from the lobule periphery to the central vein (Arias et al., 1988). The sinusoidal organization is important to the function of the liver. In order to recreate sinusoid-like organization and control its alignment, we patterned two lines of HUVEC $200 \mu \mathrm{m}$ apart on Matrigel using LGDW. Five hours later, the cells elongated into two parallel structures (Fig. 6A). We subsequently added 40,000 cells/ $\mathrm{mL}$ rat hepatocytes which rapidly adhered to the endothelial structures creating two parallel sinusoid-like structures in vitro (Fig. 6B). Liver sinusoids develop from endothelial-hepatic aggregates over a period of many weeks in vivo. Therefore, we do not expect fully developed liver sinusoids to form after a few days of in vitro culture. However, our results suggest that vascular structures can form the backbone for ex vivo liver morphogenesis, a phenomenon we can control by LGDW. Our ability to write sinusoid-like structures makes feasible the reconstruction of three-dimensional liver tissue in vitro.

\section{Ultrastructural Analysis of Random Cultures and Co-Cultures on Matrigel}

Although LGDW allows us to pattern cells with micrometer resolution on biological gels, and to form advanced structures, it is limited in its current form (a single beam) to hundreds of cells per hour. This prevented us from studying these cultures under transmission electron microscopy which requires bulk tissue samples.

To gain more insight into the development of endothelialhepatic aggregates in vitro, we analyzed samples that were
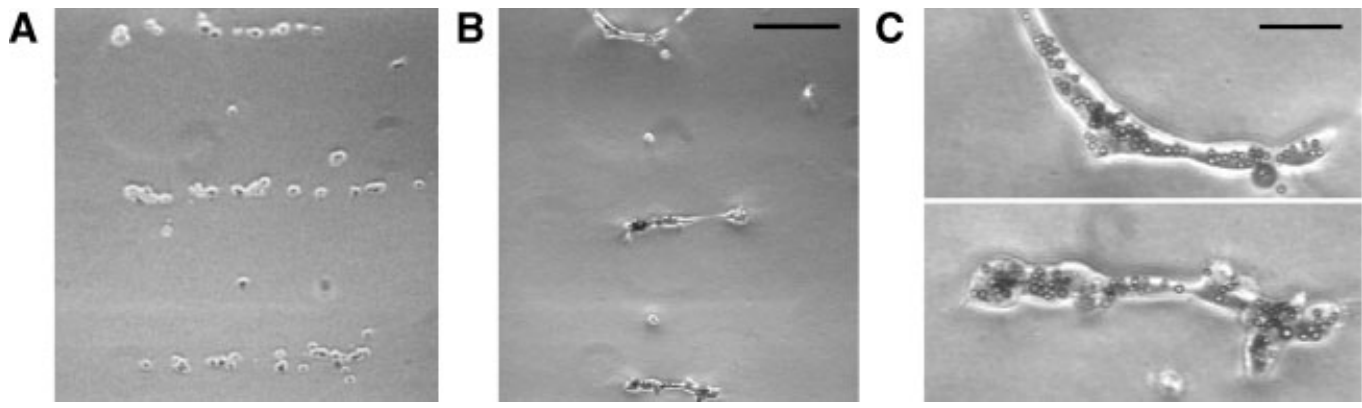

Figure 5. LGDW of vascular structures. A: Three lines of HUVEC were written on a Matrigel by LGDW. B: After $24 \mathrm{~h}$, the pattern developed into three separate elongated structures, a single cell in diameter. Bar $=200 \mu \mathrm{m}$. C: A high magnification image of two tube-like structures written on Matrigel. $\operatorname{Bar}=100 \mu \mathrm{m}$. 
A

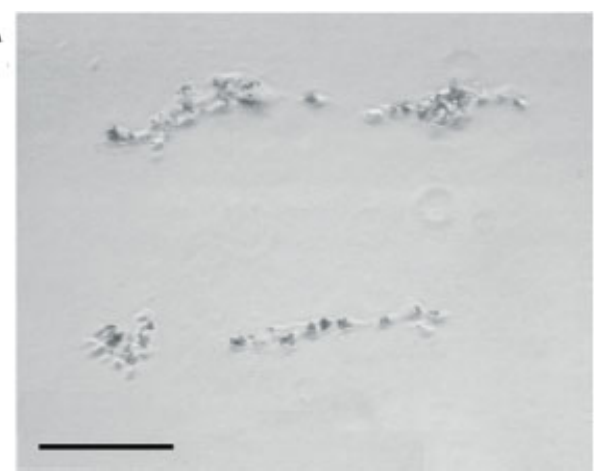

B

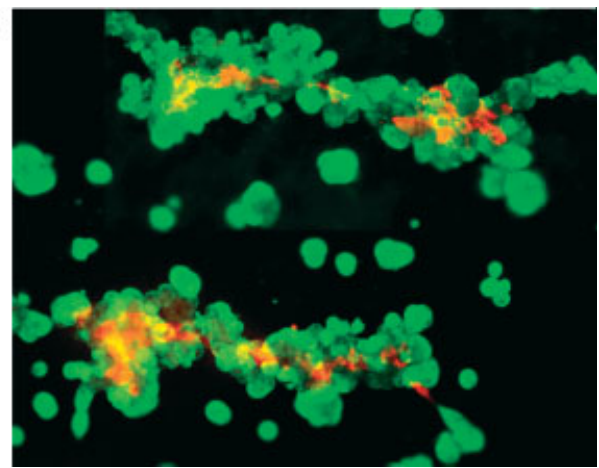

Figure 6. LGDW of liver sinusoid-like structures in vitro. A: HUVECs were patterned by LGDW in two horizontal lines on Matrigel. After 5 h in culture, the cells elongated along the pattern. B: Hepatocytes were added and $24 \mathrm{~h}$ later stained by immunofluorescence for endothelial cells (CD31, red) and hepatocytes (albumin, green). Hepatocytes aggregated around the patterned vascular structure to form a liver sinusoid-like structure in vitro. Bar $=200 \mu \mathrm{m}$.

randomly seeded with either HUVEC or HUVEC and Hepatocytes. To detect whether HUVEC vascular structures contain a lumen, we analyzed randomly seeded endothelial structures on Matrigel using transmission electron microscopy after several days of culture. Figure 7A shows an endothelial cell enclosing a lumen. The formation of lumeninclosing endothelial vascular structures on Matrigel has been previously reported (Kubota et al., 1988). A similar analysis of our HUVEC-Hepatocyte sinusoid-like structures (Fig. 7B) shows an endothelial lumen with closely associated hepatocytes. The organization of endothelial vascular structures decorated by hepatocytes has not been described previously. It is important to note that the space of Disse has not formed, suggesting these structures are not fully developed sinusoids. However, several studies suggest that the space of Disse forms between 4 and 12 weeks after liver development in vivo (Couvelard et al., 1996; McCuskey et al., 2003), our cultures might follow a similar differentiation path. In addition to ultrastructural analysis our results show that sinusoid-like structures retain cytochrome P450 gene expression and activity as well as stable albumin gene expression and secretion for over 2 months in vitro (Nahmias et al., 2005).

\section{Alternative Approaches for the Formation of Vascular Structures}

An alternative approach to patterning differentiated endothelial cells for vascular formation is to pattern the differentiation of MAPC in vitro. MAPC have been previously shown to differentiate into endothelial cells following VEGF stimulation (Reyes et al., 2002). LGDW can potentially pattern VEGF-coated beads on a monolayer of MAPC to induce endothelial differentiation along the pattern while committing all the other cells to another phenotype. We find that LGDW is capable of such spatially controlled delivery of factor-coated particles to progenitor cells, as shown in Figure 8. However, while our ability to deliver growth factorlinked particles with micrometer accuracy to stem cells is clearly shown, our preliminary results suggest MAPC differentiation into endothelial cells (assayed by CD31 staining at day 14) following such stimulation was limited. Future work will focus on using various methods of delivery of growth factors to stem cells, including the LGDW of biodegradable particles loaded with VEGF. LGDW is currently the only method able to pattern particles on living cells with micrometer precision.
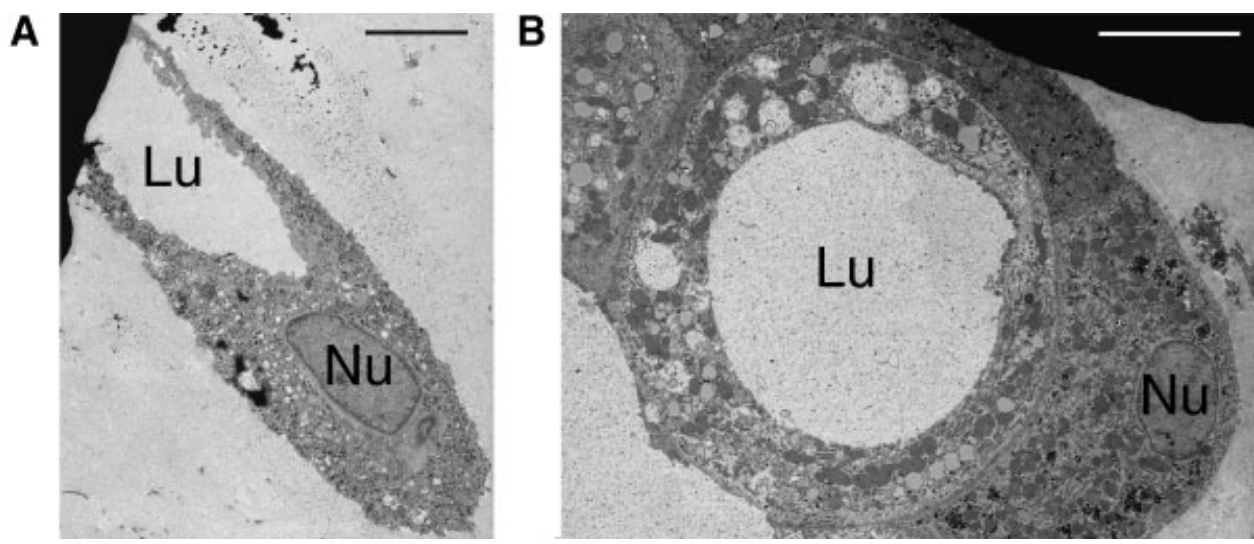

Figure 7. Transmission electron microscopy cross-sections of random culture and co-culture on Matrigel. A: A vascular structure forms on Matrigel a week after seeding. Bar $=5 \mu \mathrm{m}$. B: An endothelial vessel surrounded by aggregating Hepatocytes. Bar $=10 \mu \mathrm{m}$. Vessel lumen (Lu), nucleus (Nu). The dark regions on the top of each image are the metallic grid on which the sample lies. 


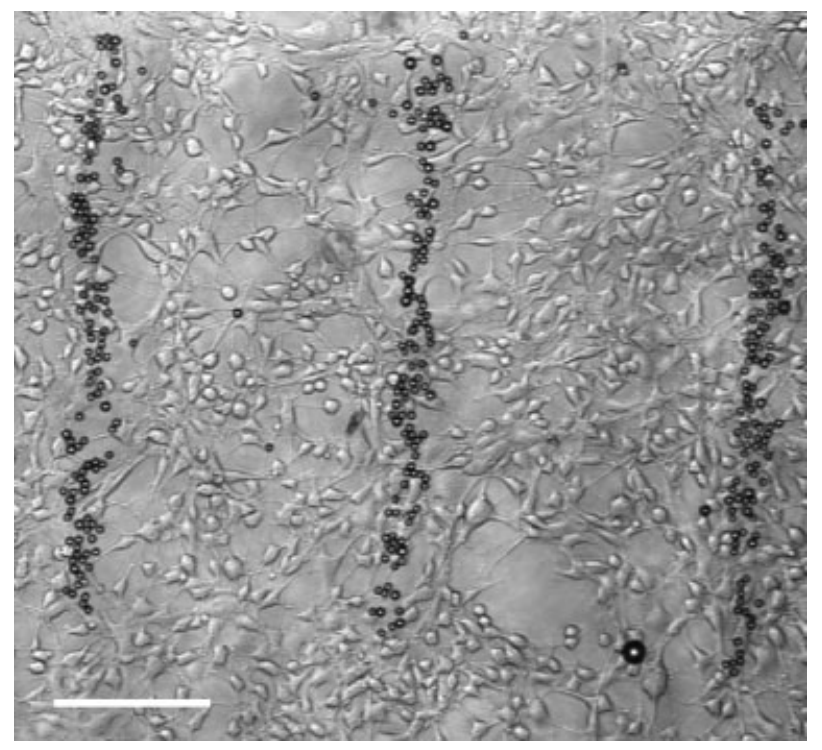

Figure 8. LGDW is able to pattern growth factor-linked bead with micrometer accuracy on stem cells monolayers. VEGF linked microbeads (10 $\mu \mathrm{m}$ diameter) were patterned on a multipotent adult progenitor cell (MAPC) monolayer. MAPC show limited differentiation (assayed by CD31 staining) following 14 days of culture, possibly due to inability of VEGF beads to signal for differentiation. Bar $=200 \mu \mathrm{m}$.

\section{CONCLUSION}

Our results demonstrate that LGDW can be used to pattern HUVEC with micrometer precision on biological gels. This ability allowed us to direct the formation of vascular structures in vitro, and an aggregate with liver sinusoid-like organization on Matrigel. To the best of our knowledge, LGDW is currently the only technique capable of patterning cells with micrometer precision on biological gels. Cell culture on mechanically compliant gels (3D culture) has been shown to be more physiologically relevant than those cultured on rigid surfaces (O'Brien et al., 2002). Thus we conclude that LGDW is uniquely suited for the study of selfassembly of tissues and heterotypic cell-cell interactions in 3D culture systems and on compliant matrices. This ability will pave the way for studying the functional significance of tissue architecture and mechanical properties at single cell resolution, and the effects of heterotypic cell-cell interactions underlying processes such as liver and pancreas morphogenesis (Cleaver and Melton, 2003), differentiation, and angiogenesis.

\section{References}

Arias IM, Jakoby WB, Popper H, Schachter D, Shafritz DA. 1988. The liver, biology and pathobiology. New York: Raven Press.

Ashkin A. 1997. Optical trapping and manipulation of neutral particles using lasers. PNAS 94(10):4853-4860.

Auerbach R, Lewis R, Shinners B, Kubai L, Akhtar N. 2003. Angiogenesis assays: A critical overview. Clin Chem 49(1):32-40.

Bhatia SN, Chen CS. 1999. Tissue engineering at the micro-scale. Biomed Microdevices 2(2):131-144.
Bhatia SN, Yarmush ML, Toner M. 1997. Controlling cell interactions by micropatterning in co-cultures: Hepatocytes and $3 \mathrm{~T} 3$ fibroblasts. J Biomed Mater Res 34:189-199.

Bhatia SN, Balis UJ, Yarmush ML, Toner M. 1999. Effect of cell-cell interactions in preservation of cellular phenotype: Cocultivation of hepatocytes and nonparenchymal cells. FASEB J 13:1883-1900.

Bicknell R, editor. 1996. Endothelial cell culture. Cambridge: Cambridge University Press.

Chiu DT, Jeon NL, Huang S, Kane RS, Wargo CJ, Choi IS, Ingber DE, Whitesides GM. 2000. Patterned deposition of cells and proteins onto surfaces by using three-dimensional microfluidic systems. PNAS 97(6): $2408-2413$.

Chrisey DB. 2000. The power of direct writing. Science 289(5481):879881.

Cleaver O, Melton DA. 2003. Endothelial signaling during development. Nature Med 9(6):661-668.

Couvelard A, Scoazec J-Y, Dauge M-C, Bringuier A-F, Potet F, Feldmann G. 1996. Structural and functional differentiation of sinusoidal endothelial cells during liver organogenesis in humans. Blood 87(11):45684580.

Deroanne CF, Lapiere CM, Nusgens BV. 2001. In vitro tubulogenesis of endothelial cells by relaxation of the coupling extracellular matrixcytoskeleton. Cardiovasc Res 49:647-658.

Dike L, Chen C, Mrksich M, Tien J, Whitesides G, Ingber D. 1999. Geometric control of switching between growth, apoptosis, and differentiation during angiogenesis using micropatterned substrates in vitro. Cell Dev Biol—Animal 25:441-448.

Dunn JCY, Tompkins RG, Yarmush ML. 1991. Long-term in vitro function of adult hepatocytes in a collagen sandwich configuration. Biotechnol Prog 7(3):237-245.

Goulet F, Normand C, Morin O. 1988. Cellular interactions promote tissuespecific function, biomatrix deposition and junctional communication of primary cultured hepatocytes. Hepatology 8(5):1010-1018.

Griffith LG, Naughton G. 2002. Tissue engineering — current challenges and expanding opportunities. Science 295:1009-1016

Gupta K, Ramakrishnan S, Browne PV, Solovey A, Hebbel RP. 1997. A novel technique for culture of human dermal microvascular endothelial cells under either serum-free or serum-supplemented conditions: Isolation by panning and stimulation with vascular endothelial growth factor. Exp Cell Res 230(2):244-251.

Koike N, Fukumura D, Gralla O, Au P, Schechner JS, Jain RK. 2004. Creation of long-lasting blood vessels. Nature 428:138-139.

Kubota Y, Kleinman HK, Martin GR, Lawley TJ. 1988. Role of laminin and basement membrane in the morphological differentiation of human endothelial cells into capillary-like structures. J Cell Biol 107:15891598.

Liu VA, Bhatia SN. 2002. Three-dimensional photopatterning of hydrogels containing living cells. Biomed Microdevices 4(4):257-266.

McCuskey RS, Ekataksin W, LeBouton AV, Nishida J, McCuskey MK, McDonnell D, Williams C, Bethea NW, Dvorak B, Koldovsky O. 2003. Hepatic microvascular development in relation to the morphogenesis of hepatocellular plates in neonatal rats. Anat Rec Part A 275A(1):10191030.

Nahmias YK, Gao BZ, Odde DJ. 2004. Dimensionless parameters for the design of optical traps and laser guidance systems. Appl Opt 43(20): 3999-4006.

Nahmias Y, Schwartz RE, Wei-Shou H, Verfaillie CM, Odde DJ. 2005. Endothelium-mediated hepatocyte recruitment in the establishment of liver-like tissue in vitro. Submitted for publication.

O'Brien LE, Zegers MMP, Mostov KE. 2002. Building epithelial architecture: Insights from three-dimensional culture models. Nature Rev 3:531-537.

Odde DJ, Renn MJ. 1999. Laser-guided direct writing for applications in biotechnology. Trends Biotechnol 17:385-389.

Odde DJ, Renn MJ. 2000. Laser-guided direct writing of living cells. Biotechnol Bioeng 67(3):312-318.

Renn MJ, Pastel R. 1998. Particle manipulation and surface patterning by laser guidance. J Vacuum Sci Technol B 16(6):3859-3863. 
Renn MJ, Montgomery D, Vdovin O, Anderson DZ, Wieman CE, Cornell EA. 1995. Laser-guided atoms in hollow-core optical fibers. Phys Rev Lett 75(18):3253-3256.

Reyes M, Lund T, Lenvik T, Aguiar D, Koodie L, Verfaillie CM. 2001. Purification and ex vivo expansion of postnatal human marrow mesodermal progenitor cells. Blood 98(9):2615-2625.

Reyes M, Dudek A, Jahagirdar B, Koodie L, Marker P, Verfaillie C. 2002. Origin of endothelial progenitors in human postnatal bone marrow. J Clin Invest 109(3):337-346.

Schwartz RE, Reyes M, Koodie L, Jiang Y, Blackstad M, Lund T, Lenvik T, Johnson S, Hu W-S, Verfaillie CM. 2002. Multipotent adult progenitor cells from bone marrow differentiate into functional hepatocyte-like cells. J Clin Invest 109(10):1291-1302.

Seglen PO. 1976. Preparation of isolated rat liver cells. Methods Cell Biol 13:29-83.

Shakado S, Sakisaka S, Noguchi K, Yoshitake M, Harada M, Nimura Y, Sata M, Tanikawa K. 1995. Effects of extracellular matrices on tube formation of cultured rat hepatic sinusoidal endothelial cells. Hepatology 22(3):969-973.

Strain AJ, Neuberger JM. 2002. A bioartificial liver-state of the art. Science 295(5557):1005-1009. 